\title{
A MICROSTRUCTURAL AND MECHANICAL PROPERTIES COMPARISON OF P/M 718 AND P/M TA 718
}

\author{
Andrea R. Braun and John F. Radavich \\ Purdue University West Lafayette, IN 47907 \\ Charles P. Stinner \\ Cytemp Specialty Steels Bridgeville, PA 15017
}

\begin{abstract}
The effects of $\mathrm{Ta}$ on phases and mechanical properties in conventional 718 type compositions have not been fully explored. While $\mathrm{Ta}$ and $\mathrm{Nb}$ have similar atomic sizes, the solubility of Ta in nickel is much greater than that of $\mathrm{Nb}$. This difference in solubility would affect the initial segregation on solidification and subsequent phase reactions. To study the role of $\mathrm{Ta}$ in phase reactions and on alloy stability in a homogeneous material, a comparative study of conventional $\mathrm{P} / \mathrm{M} 718$ and $\mathrm{P} / \mathrm{M}$ Ta 718 was undertaken.

The results of this study showed that the heat treatment used for conventional 718 did not produce an significant strengthening phases in Ta 718 and a modified heat treatment was necessary to precipitate $\gamma^{\prime \prime}$ and $\gamma$ strengthening phases. The $\gamma^{\prime \prime}$ phase in Ta 718 is still presert at $1750^{\circ} \mathrm{F}$. The $\gamma^{\prime}$ to delta transition in Ta 718 is more sluggish and occurs at higher temperatures than in conventional 718 materials. Data from tensile tests at $1400^{\circ} \mathrm{F}$ indicates that Ta 718 has a higher temperature capability than conventional 718 .
\end{abstract}

\section{Introduction}

$\mathrm{Ta}$ and $\mathrm{Nb}$ atoms are generally believed to have similar effects on structures in high temperature superalloys, largely because of their similar atomic size and location in the periodic table. The role of $\mathrm{Ta}$ in $\mathrm{Ni}$-based superalloys has been the subject of numerous papers, but the effect of Ta in Alloy 718 has not been fully explored. In Alloy 718, $\mathrm{Nb}$ has been shown to be not only part of the strengthening phases, but also the main cause of segregation because of its limited solubility in $\gamma$ matrix. Homogenization efforts to eliminate the Laves phase and diffuse the $\mathrm{Nb}$ are time consuming since the rate of diffusion of $\mathrm{Nb}$ is slow, and large amounts of residual segregation are commonly found in so-called homogenized materials.

Recently, Loewenkamp, Radavich, and Kelly studied the effects of a one to one atomic base substitution of $\mathrm{Ta}$ for $\mathrm{Nb}$ in cast Alloy 718. Their study showed that $\mathrm{Ta}$ reduced the amount of initial segregation which they attributed to the higher solubility of Ta in the $\gamma$ matrix. More importantly, Ta additions, similar to $\mathrm{Nb}$, were found to produce strengthening $\gamma^{\prime \prime}$ phase. This $\gamma^{\prime \prime}$ phase was still present at temperatures up to 1800F. The transition of the $\gamma^{\prime \prime}$ to $\delta$ phase found in Alloy 718 was not obvious in the cast Ta-modified 718.

In the study by Loewenkamp, Radavich, and Kelly, the pattern of $\gamma^{\prime \prime}$ precipitation at $1800 F$ suggested that residual segregation was present and that it would influence the temperature of stability of both the $\delta$ and $\gamma^{\prime \prime}$ phases. To eliminate the segregation effects on

\footnotetext{
Superalloy 718 - Metallurgy and Applications Edited by E.A. Loria
}

The Minerals, Metals \& Materials Society, 1989 
phase behavior, especially the strengthening $\gamma^{\prime}$ phase, a program was carried out to characterize the phases formed in alloy 718 to the phases in Ta 718 using homogeneous consolidated powder samples. The important goals of this program were to study the effect of Ta on the precipitation and stability of $\gamma^{\prime}$ and relate the $\gamma^{\prime}$ behavior to mechanical properties.

\section{Materials Preparation}

The Alloy 718 and Ta 718 powders were produced using argon atomization and commercial rapid solidification processes. The compositions of the powders produced are shown in Table 1.

Table 1: Alloy Compositions

\begin{tabular}{c|c|c|c|c|c|c|c|c|c|c|c}
\hline wt\% & $\mathrm{Ni}$ & $\mathrm{Cr}$ & $\mathrm{Fe}$ & $\mathrm{Nb}$ & $\mathrm{Ta}$ & $\mathrm{Mo}$ & $\mathrm{Ti}$ & $\mathrm{Al}$ & $\mathrm{B}$ & $\mathrm{C}$ & $\mathrm{S}$ \\
\hline TA 718 & 48.5 & 20.4 & 18.9 & - & 7.2 & 3.3 & 0.9 & 0.5 & 0.001 & 0.03 & 0.01 \\
Alloy 718 & 52.5 & 18.5 & 18.5 & 5.1 & - & 3.0 & 0.9 & 0.5 & 0.005 & 0.04 & 0.003
\end{tabular}

Both powder products were consolidated at atmospheric pressure (CAP) and were hot rolled at $2025 \mathrm{~F}$ and heat treated at $1825 \mathrm{~F} / 1 \mathrm{hr}$. $/ \mathrm{WC}+1325 \mathrm{~F} / 8 \mathrm{hrs}$./FC to $1150 \mathrm{~F} / 8 \mathrm{hrs}$./AC.

Room temperature tensile, $1200 \mathrm{~F}$ tensile, and stress rupture tests were carried out. For Ta $718,1400 \mathrm{~F}$ tensile tests were also conducted. Microstructural characterization was performed using scanning electron microscopy, and phase identification was carried out using EDAX analysis and X-ray diffraction. Diffraction samples were prepared from residue of phase extractions using a 10\% $\mathrm{HCl}$-Methanol solution with a Ta cathode at 5 volts for approximately 2 hours.

The sample preparation for the SEM study was as follows:

1. Mechanical polish to 600 grit $\mathrm{SiC}$ paper and $6 \mu$ diamond polish.

2. Electropolish using a stainless steel beaker as the cathode and a solution of $20 \% \mathrm{H}_{2} \mathrm{SO}_{4}$ and $80 \%$ Methanol. Polishing time was 20 seconds at 5 volts.

3. Electrolytic etch in a $\mathrm{CrO}_{3}$ etchant ( $172 \mathrm{cc} \mathrm{H}_{3} \mathrm{PO}_{4}, 10 \mathrm{cc} \mathrm{H}_{2} \mathrm{SO}_{4}, 16 \mathrm{~g} \mathrm{CrO}$ ) for 10 seconds at 5 volts.

\section{Mechanical Properties Analysis}

The results of the room temperature tensile and $1200 \mathrm{~F}$ tensile tests for both conventional 718 and $\mathrm{Ta} 718$ are shown in Figure 1 along with comparative literature values for the same heat treatment. The lower results for the Ta-modified product are due to the lack of adequate strengthening precipitates and porosity resulting from low densification of the Ta 718 . The conventional Alloy 718 properties are also lower than comparative literature values as a result of the same low densification.

Fractography micrographs of the room temperature tensile samples, Figures $2 \mathrm{~A}$ and $2 \mathrm{~B}$, illustrate the presence of residual porosity due to the lack of complete consolidation of the powder. When the consolidated samples were fully $100 \%$ dense, the mechanical properties improved dramatically. The important effect of densification on mechanical properties is shown in Figure 3.

\section{Heat Treatment Study}

SEM studies of the heat treated Ta 718 material showed very little precipitation of the $\gamma^{\prime \prime}$ and $\gamma^{\prime}$ strengthening phases when given the standard $1325^{\circ} \mathrm{F}$ to $1150^{\circ} \mathrm{F}$ age. The comparison in strengthening phase precipitation between Alloy 718 and Ta 718 is shown in Figures $4 \mathrm{~A}$ and 4B. The precipitation in the Ta 718 is very difficult to resolve even at $30 \mathrm{~K}$ magnification indicating the standard heat treatment was too low for Ta 718. Both figures show precipitated particles that are finely dispersed. Although Alloy 718 shows a greater dispersion of strengthening particles, neither alloy shows sufficient precipitation for optimum mechanical properties as evidenced by the high magnification necessary to view the $\gamma^{\prime \prime}$ and $\gamma^{\prime}$ particles. 


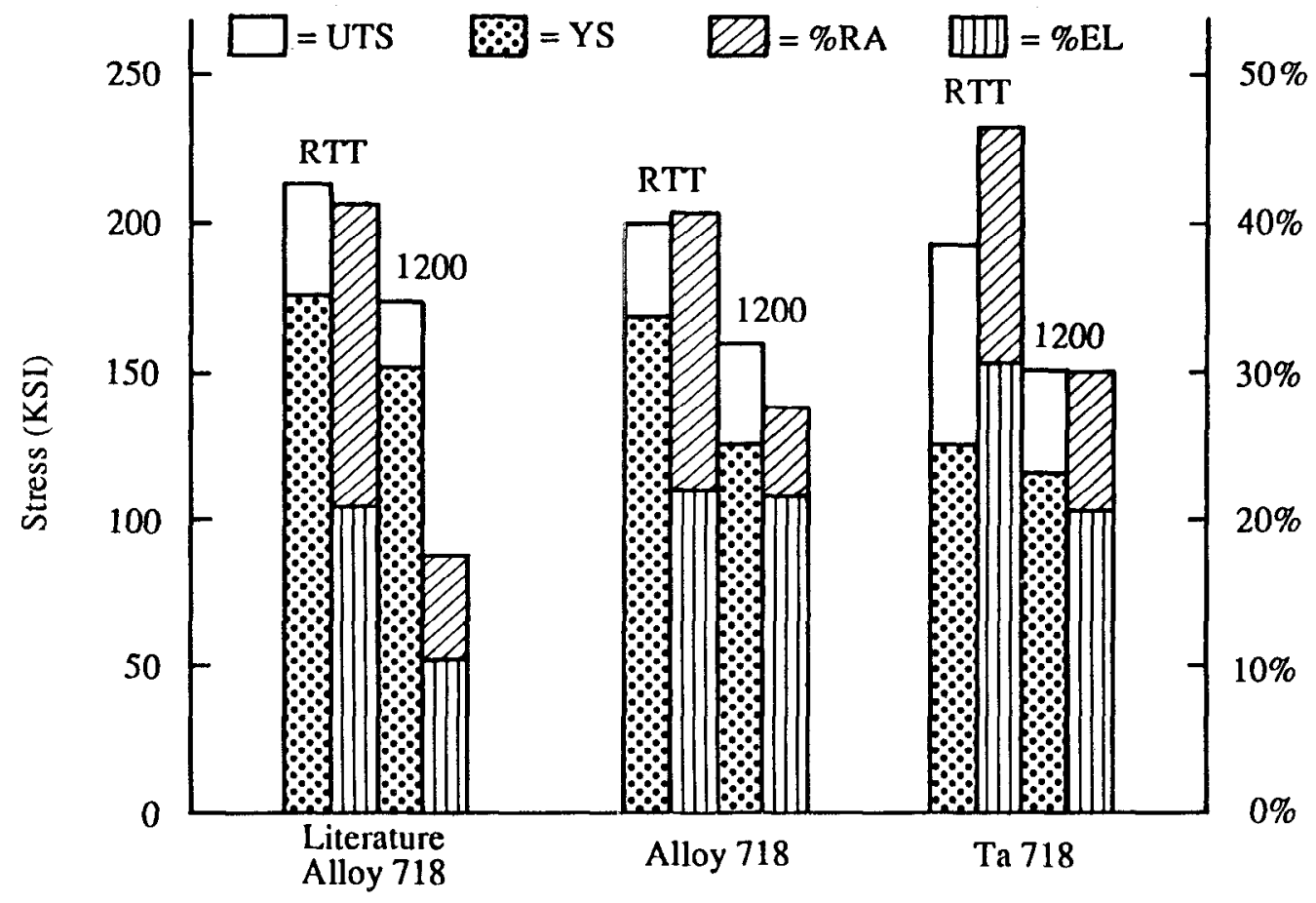

Figure 1: Mechanical Properties at Conventional Heat Treatment

In order to optimize the mechanical properties of $\mathrm{Ta} 718$, a series of heat treatments were carried out to produce a strengthening phase in Ta 718. Hardness tests were run to verify hardness changes which would indicate the precipitation of strengthening phases. As a result of these tests, a modified heat treatment of $1600 \mathrm{~F} / 1 \mathrm{hr}$. $+1350 \mathrm{~F} / 6 \mathrm{hrs}$. was selected and given to the Ta 718 samples and additional mechanical testing was performed.

Figure $4 \mathrm{C}$ shows the precipitation in the Ta 718 samples given the modified heat treatment. The size of the $\gamma^{\prime \prime}$ is much larger than in the conventional 718 heat treatment. The response of the $\gamma^{\prime \prime}$ to the modified heat treatments suggests that the size of the $\gamma^{\prime}$ precipitation can be modified further for higher strengthening. A comparison of mechanical properties, shown in Figure 5, indicates higher tensile strengths with the new heat treatment. In addition, a $1400 \mathrm{~F}$ tensile test on the modified heat treatment samples showed a substantial strength retention at elevated temperatures than found in comparable alloy 718.

\section{Stability Testing}

The mechanical properties analysis and the structures formed in the modified heat treatment study provided convincing evidence that the strengthening phases of Ta 718 do not precipitate in the same low temperature ranges as the conventional alloy. This indicated a greater potential for phase stability at higher temperatures compared to the conventional alloy. It has been shown that in the $1500 \mathrm{~F}$ to $1600 \mathrm{~F}$ temperature range, the $\gamma^{\prime \prime} \rightarrow \gamma+\delta \rightarrow \delta$ transition occurs rapidly in Alloy 718. In the final stage of the $\delta$ plate phase transition some $\gamma$ is left in the matrix before complete transformation to $\delta$ plates. In the transition of $\gamma^{\prime \prime} \rightarrow \delta$ phase in the Ta 718 , the precipitation of the $\gamma$ is absent near the $\delta$ plates.

Figure $6 \mathrm{~A}$ shows microstructural changes for conventional 718 when exposed to $1500 \mathrm{~F}$ for 100 hours. These structures show the final stages of the $\delta$ plate phase transition. The effects on microstructure in Ta 718 exposed for 100 hours are shown in Figure 6B. These micrographs indicate that almost no $\delta$ plate phases have formed in the Ta-modified product. $\gamma^{\prime \prime}$ particles are still present in the matrix indicating that the mechanical properties of Ta 718 after this exposure would be higher than those of conventional 718 . 


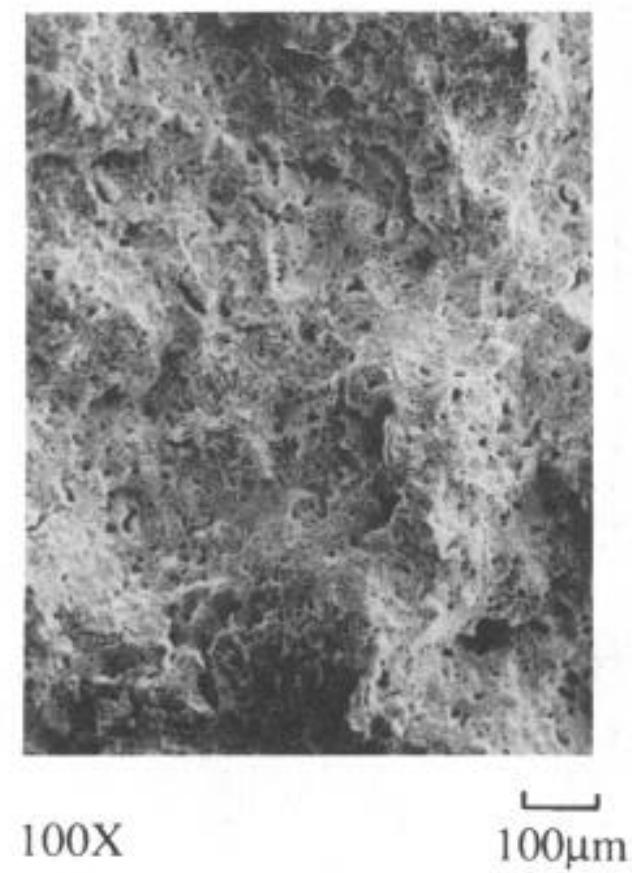

Figure 2A: Fracture Surface of Alloy 718 RTT Sample

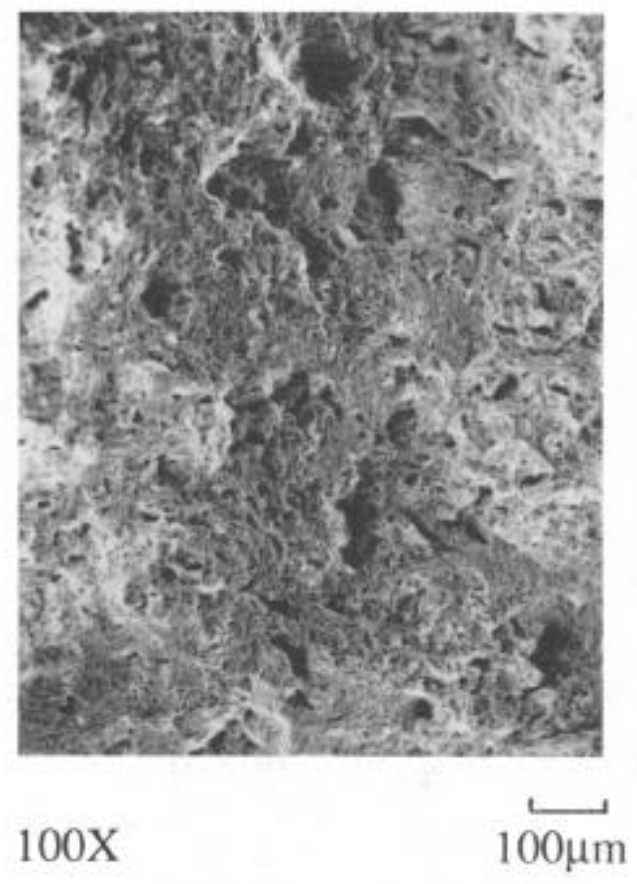

Figure 2B: Fracture Surface of Ta 718 RTT Sample

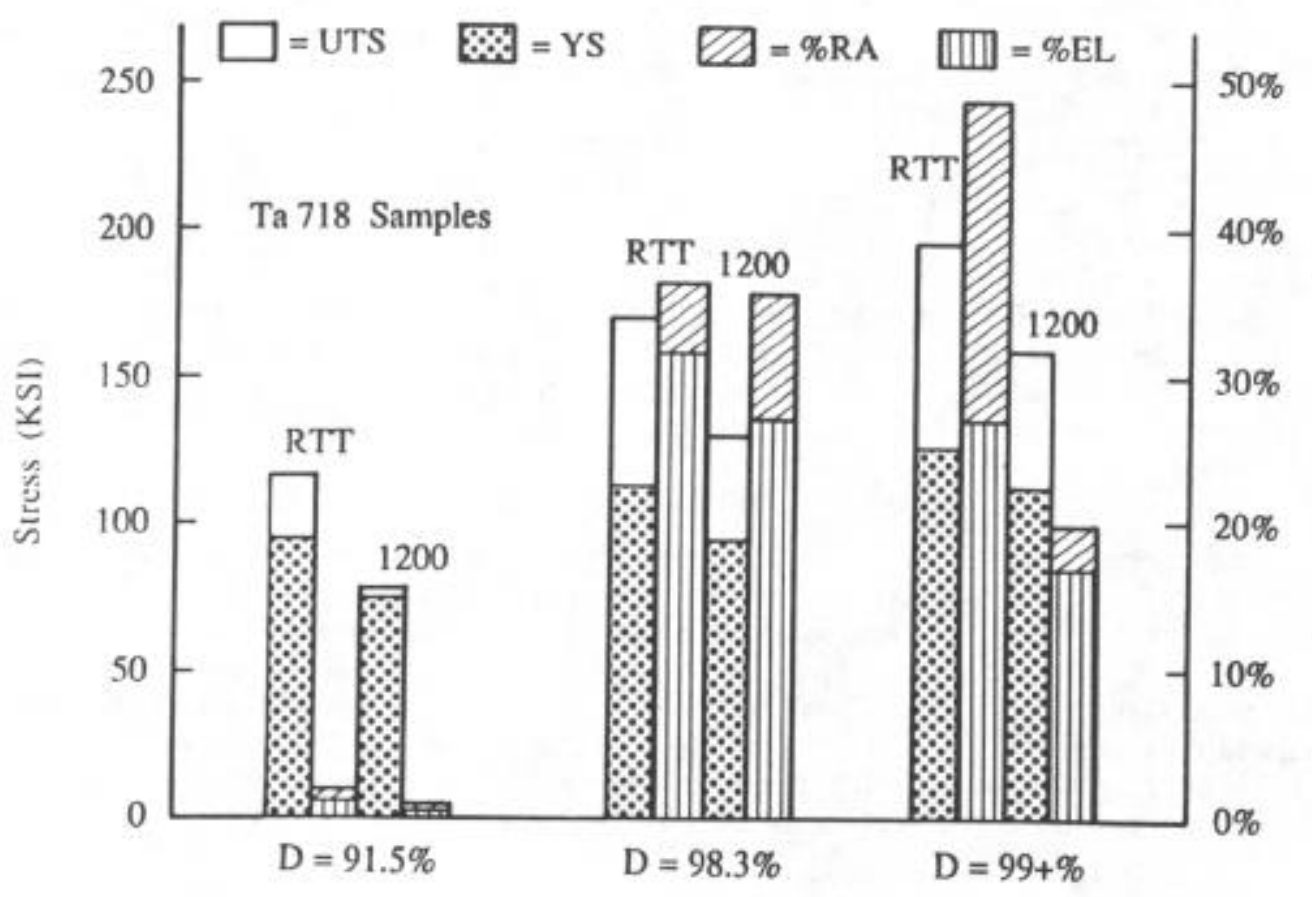

Figure 3: Comparison of Mechanical Properties with Densification 


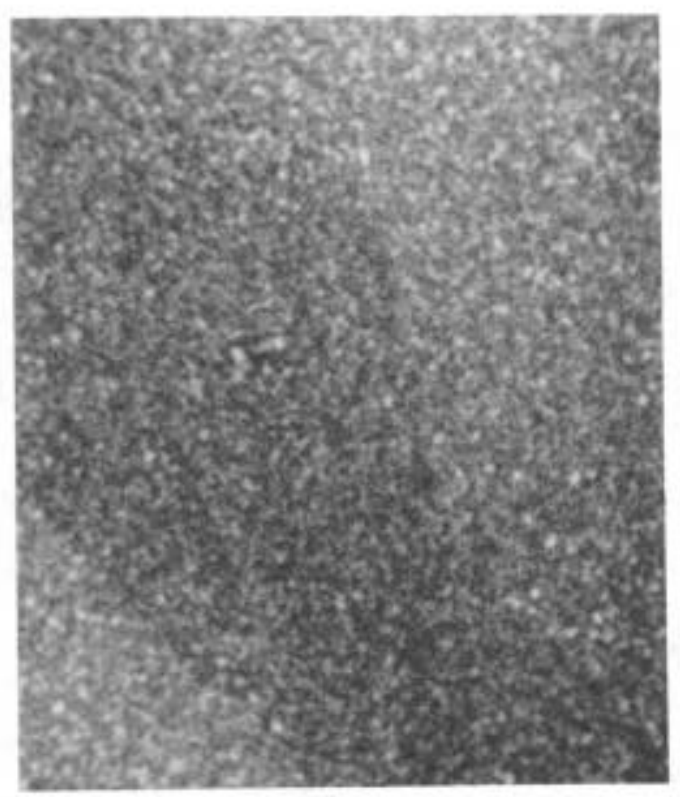

$30000 \mathrm{X}$

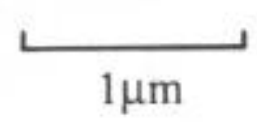

Figure 4A: Alloy 718 with Conventional lleat Treatment

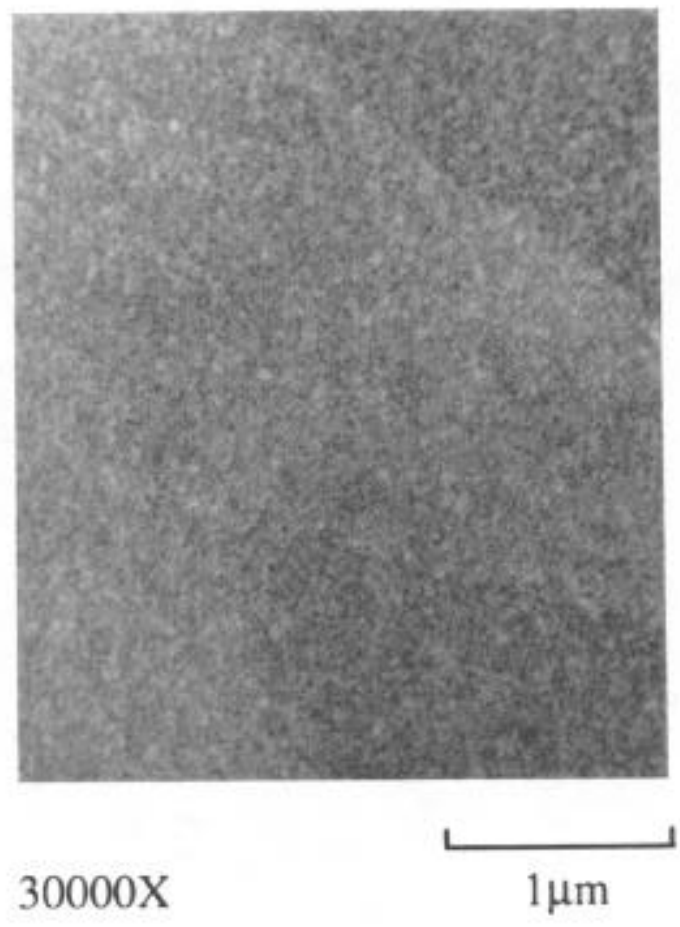

Figure 4B: Ta 718 with Conventional Heat Treatment

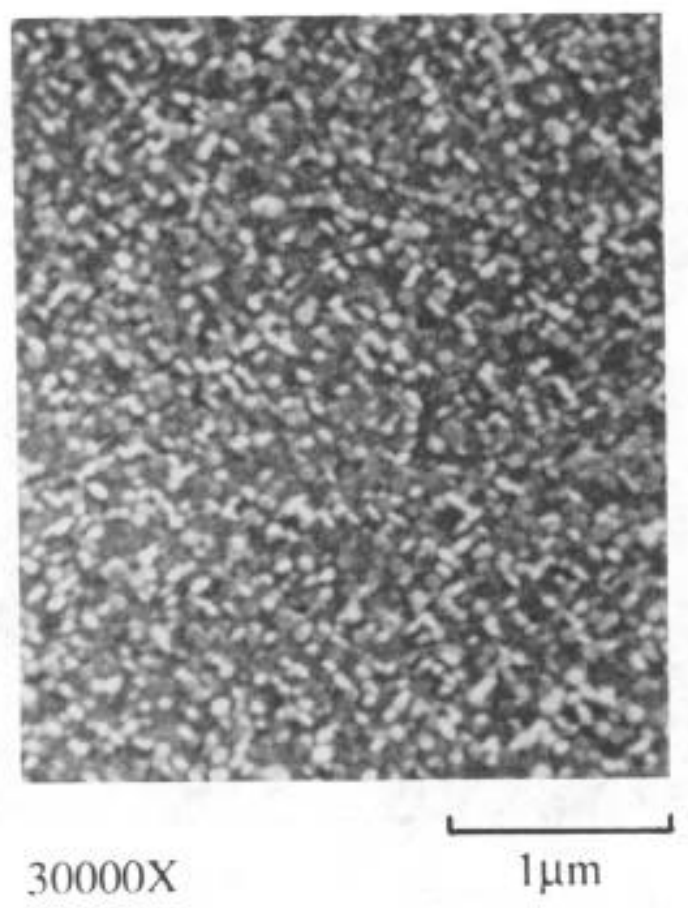

Figure 4C: Ta 718 with

Modified llealt Treatment 


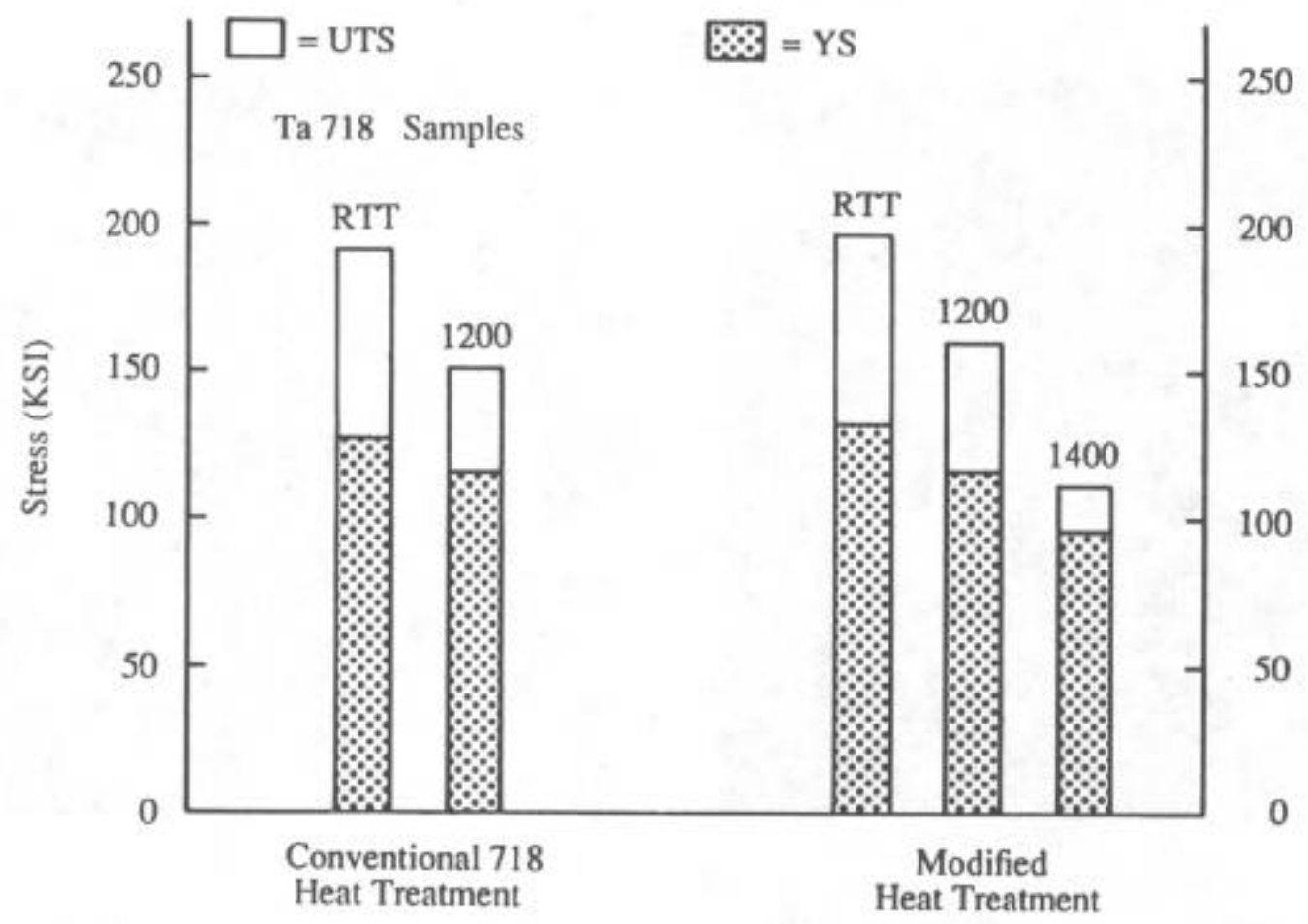

Figure 5: Comparison of Mechanical Properties at Modified Heat Treatment

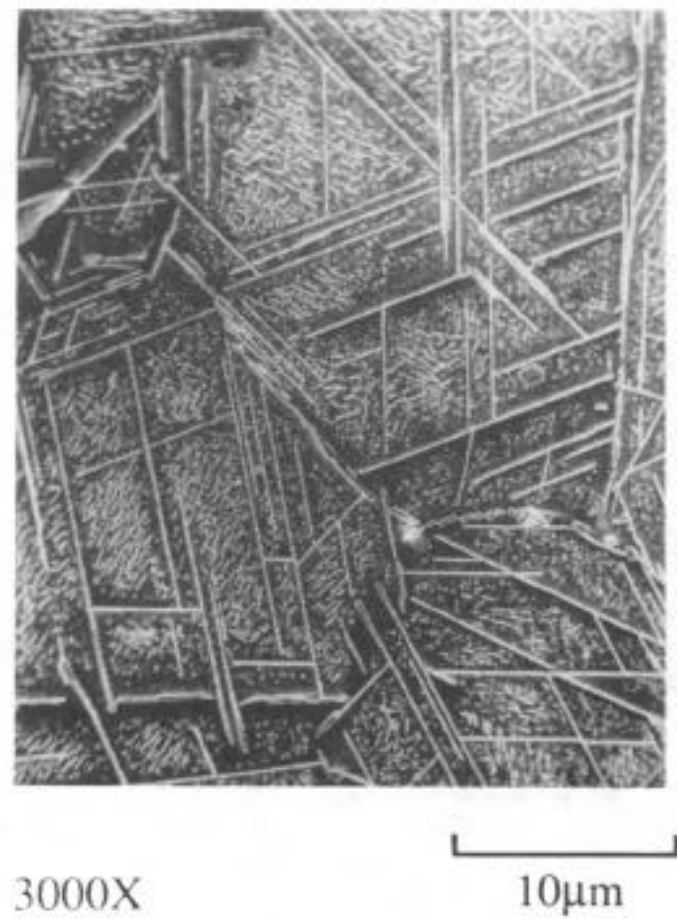

Figure 6A: Alloy 718 1500F/100 hrs.

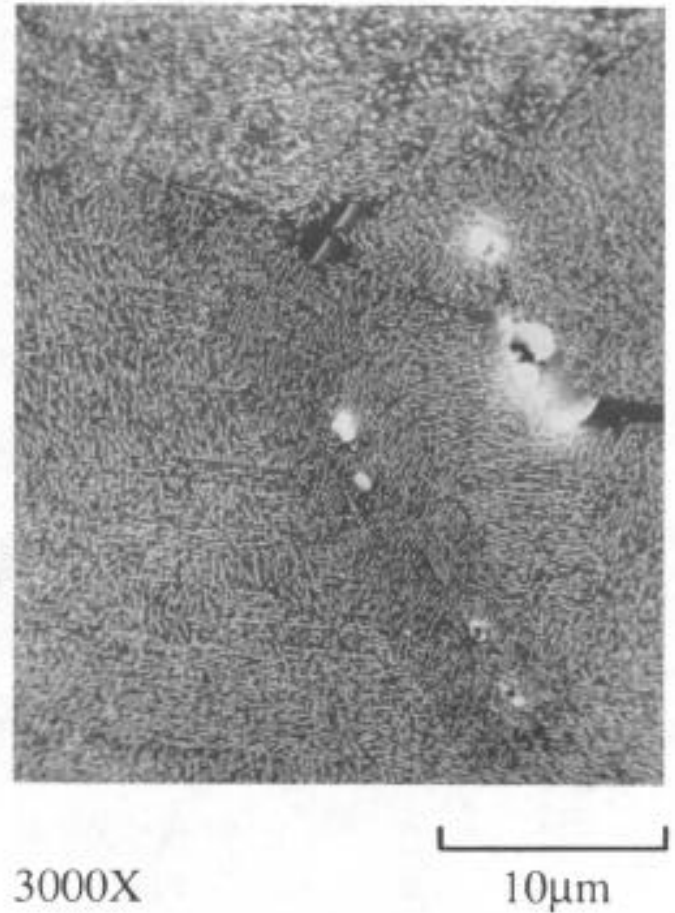

Figure 6B: Ta 718 1500F/100 hrs. 


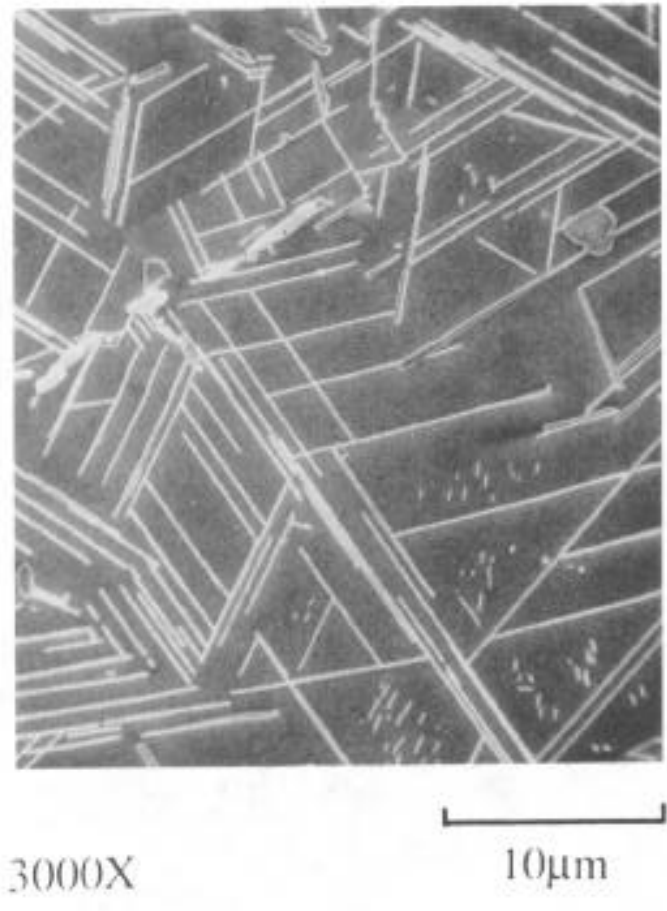

Figure 60 : Alloy 718 I6001:/ 50 hars.

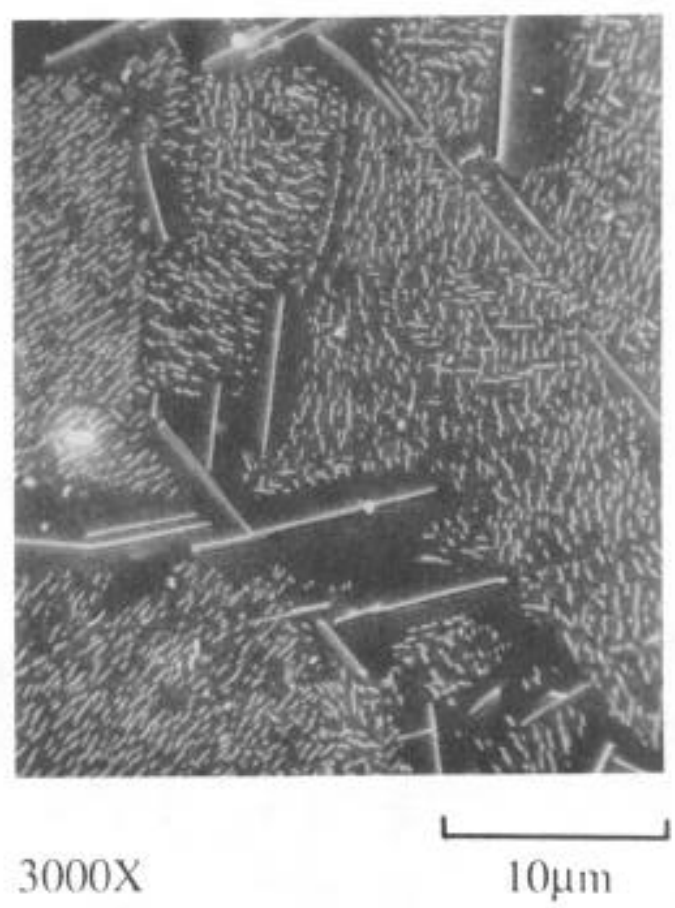

Figure 61): T:1 718 1600F/ 50 hrs.

The structures formed after a $1600 \mathrm{~F} / 50 \mathrm{hr}$. exposure on Alloy 718 is shown in Figure 6C. All the strengthening phases have completely transformed to $\delta$ plates. For Ta 718 , some $\delta$ plates have formed, but the matrix still contains many $\gamma^{\prime \prime}$ particles as shown in Figure 6D. These stability photographs convincingly indicate the greater phase stability of the Ta-modified alloy in the $1500-1600 \mathrm{~F}$ range.

\section{Conclusions}

The following conclusions may be drawn from this work:

- Mechanical properties for Ta 718 were not optimum because of porosity and the use of a non-optimal heat treatment

- For the same low temperature heat treatments, Ta 718 showed less response to phase precipitation than conventional 718 indicating higher temperature stability of precipitating phases

- A modified heat treatment of $1600 \mathrm{~F} / 1 \mathrm{hr}$. $+1350 \mathrm{~F} / 6 \mathrm{hrs}$. produced $\gamma^{\prime \prime}$ precipitation which gave more reproducible properties.

- Data from the $1400 \mathrm{~F}$ tensile test indicated higher strengths potential in Ta 718 than conventional Alloy 718 .

- Elevated temperature exposures shows less tendency toward $\delta$ transition in Ta 718

\section{Acknowledgements}

Special thanks to Cytemp Specialty Steels Powder Products Division for supplying the materials and mechanical property data. 